\title{
STUDY OF THE ZEOLITIZATION PROCESS OF FLY ASH USING AN ORTHOGONAL ARRAY OF TAGUCHI EXPERIMENTAL DESIGN
}

\author{
A. MEDINA R*., P. GAMERO M., J. M. ALMANZA R., D. A. CORTÉS H. AND G. VARGAS G. \\ Centro de Investigación y Estudios Avanzados del IPN. Unidad Saltillo. \\ Carretera Saltillo-Mty Km. 13.5 Ramos Arizpe, Coah. Mex. C.P. 25900 A.P. 663. \\ (Received: November 20, 2008 -Accepted: June 17, 2009)
}

\begin{abstract}
Zeolitization of fly-ash by a direct route and a fusion method (two-step process) was studied using an orthogonal array of Taguchi experimental design. The effect of different processing conditions, such as type and concentration of the mineralizing agent, fusion and crystallizing temperatures and times and stirring speed, on the quantity of the zeolitic phase obtained, were evaluated. By means of a variance analysis, the contribution of the processing conditions to the response variable (content of zeolitic phase, wt $\%$ ) was evaluated. According to the results, the statistical significant processing conditions that show a stronger effect on the zeolite content were the type of mineralizing agent and crystallizing temperature. The optimal conditions for obtaining 5 types of zeolites were also determined. The type of zeolite depends mainly on the nature of the mineralizing agent. When using the direct method potassium hydroxide (KOH) was the optimal mineralizing agent, leading to a material with $77 \mathrm{wt} \%$ of zeolitic phase. On the other hand, when using the fusion method the optimal alkaline agent was sodium hydroxide $(\mathrm{NaOH})$ reaching up to $91 \mathrm{wt} \%$ of zeolitic material.
\end{abstract}

Keywords: Fly ash, Zeolites synthesis, Zeolitization, Taguchi array, Statistical analysis.

\section{INTRODUCTION}

Fly ash is a waste generated from the mineral coal combustion in thermoelectric plants. Health risks generated by fly ash are related to its low density, hollow spherical shape and particle size ${ }^{1}$. A fraction of fly ash is constituted by particles $\leq 10 \mu \mathrm{m}$, which can be incorporated to inhalable particle material $\left(\mathrm{PM}_{10}\right)$ increasing the respiratory diseases, pulmonary damage, and mortality among exposure population ${ }^{2}$

Since 1950 main application of fly ash is as an additive in the cement and concrete industry ${ }^{3}$. Recently, research has also been performed in the aim of improving the uses of fly ash and transforms it in a material with high aggregated value $^{4-7}$. One of these research lines focuses on the synthesis of zeolites from this waste material. Zeolites are crystalline and hydrated aluminosilicates that possess a wide gamma of applications, such as ionic exchangers, molecular sieves, catalysts and adsorbents ${ }^{8}$.

A great number of studies ${ }^{9-12}$ have been directed to the conversion of fly ash into zeolitic materials by hydrothermal treatments. These treatments involve the dissolution of the highly polymerized $\mathrm{Si}$ and $\mathrm{Al}$ species in an alkaline solution, followed by a crystallizing stage in which, the ring-like structures needed for the zeolite construction, are formed.

The type and quality of the obtained zeolite depend on the hydrothermal treatment conditions, such as the sources of $\mathrm{Si}$ and $\mathrm{Al}$, the nature of the alkaline agent, temperature, time, concentration, ageing time and $\mathrm{pH}$.

Despite the great number of reported studies about the synthesis of zeolitic materials, it is important to determine the effect of the parameters involved in the transformation of fly ash into zeolites and to optimize this process Even though research has been directed with this objective ${ }^{11,13-14}$, it has not been reported the use of statistical methods to determine the effect of the experimental conditions and thus to establish their optimal values for the zeolite synthesis. The knowledge of the contribution of each of these experimental conditions (individual factors) is an important key to decide the nature of the control to be established in the process. In order to evaluate the contribution percentage of each of the factors, the variance analysis is the most common statistical treatment applied to the results obtained from an experiment. Thus, this analysis leads to determine which of the factors need to be controlled and which are not ${ }^{15}$.

In the present work, mexican fly ash was used as the $\mathrm{Si}$ and $\mathrm{Al}$ source to obtain zeolites. Two synthesis methods were evaluated; a) conventional hydrothermal treatment (direct method) and b) alkali fusion followed by hydrothermal treatment (fusion method). The effect of the following factors on the crystallinity of the zeolitic phase was evaluated: i) nature of the alkaline agent, ii) fusion temperature and time, iii) crystallizing temperature and time, iv) alkaline agent concentration and v) stirring speed. This study was performed using an orthogonal array of Taguchi experimental design. For each of the zeolitic phase obtained, the optimal experimental conditions were also determined.

\section{EXPERIMENTAL}

\section{Materials}

A sample of fly ash of $200 \mathrm{Kg}$ was obtained from a thermoelectric plant situated in north Mexico. The sample was dried overnight at $105^{\circ} \mathrm{C}$. Table 1 shows the chemical composition of this fly ash. The value of $\mathrm{SiO}_{2}+\mathrm{Al}_{2} \mathrm{O}_{3}+\mathrm{Fe}_{2} \mathrm{O}_{3}$ is higher than the $80 \%$ and the $\mathrm{CaO}$ content is lower than $10 \%$, thus, according to the ASTM C618 standard, this fly ash is of Class $\mathrm{F}^{16}$.

For the zeolitization, hydroxides of sodium, lithium and potassium (reagent grade chemicals, Riedel-de Haien) were used. Sodium aluminate and silicate were obtained from spectrum.

Table 1. Chemical composition of fly ash (wt \%)

\begin{tabular}{|c|c|c|c|c|c|c|c|c|}
\hline $\mathbf{S i O}_{2}$ & $\mathbf{A l}_{2} \mathbf{O}_{3}$ & $\mathbf{F e}_{2} \mathbf{O}_{3}$ & $\mathbf{C a O}$ & $\mathbf{K}_{2} \mathbf{O}$ & $\mathbf{T i O}_{2}$ & $\mathbf{S O}_{3}$ & $\mathbf{M g O}$ & $\mathbf{N a}_{2} \mathbf{O}$ \\
\hline 56.70 & 23.74 & 5.97 & 3.98 & 1.49 & 1.09 & 0.65 & 0.73 & 0.40 \\
\hline $\mathrm{ZrO}_{2}$ & $\mathbf{S r O}$ & $\mathbf{P}_{2} \mathbf{O}_{\mathbf{5}}$ & $\mathbf{N i O}$ & $\mathbf{C u O}$ & $\mathbf{M n O}$ & $\mathbf{Z n O}$ & $\mathbf{L O I}$ & \\
\hline 0.05 & 0.04 & 0.048 & 0.02 & 0.025 & 0.024 & 0.017 & 5.06 & \\
\hline
\end{tabular}

\section{Experimental design}

In the aim of studying the effect of the experimental conditions on the zeolitization process of the fly ash selected, an orthogonal array of Taguchi experimental design was used. This array allows a consisting and balanced design and its advantage is the possibility of defining the optimal conditions of the process by means of the variance analysis ${ }^{15}$.

Globally, seven factors were evaluated: nature and quantity of the alkaline agent, fusion temperature and time, crystallizing temperature and time and stirring speed. Each factor was studied at three levels. The synthesis was performed by two different routes, direct and fusion methods. For each of the methods an $\mathrm{L}_{27}(3)^{13}$ orthogonal array was used. The response variable was the percentage of crystalline zeolitic phase. In the following section, the factors and levels evaluated for each method, as well as the procedure used, are described.

\section{Synthesis of zeolites}

The experiments were carried out in a set of 8 serial-connected high pressure stainless steel reactors (Parr $ß)$ with a capacity of $100 \mathrm{ml}$. The crystallizing conditions were programmed by means of the Specview software. The direct method was based on the conventional hydrothermal treatment and the indirect method consisted in a heat treatment of the fly ash in contact with the alkaline agent, followed by the crystallization stage.

\section{Direct method}

In this synthesis route the quantity of fly ash and the $\mathrm{H}_{2} \mathrm{O} / \mathrm{SiO}_{2}$ ratio were kept constants. Five factors at three levels each were evaluated (Table 2).

The procedure was as follows: the mineralizing agent was dissolved into deionized water and the resulting solution was poured into the Parrß reactor. Then, the fly ash was added and the container was hermetically closed. 
The crystallizing temperature and time were set and once the hydrothermal treatment was finished, the product was recollected, washed with deionized water and dried at $100^{\circ} \mathrm{C}$ overnight.

Table 2. Factors and levels evaluated in the direct method.

\begin{tabular}{|c|c|c|c|c|}
\hline & FACTOR & Level 1 & Level 2 & Level 3 \\
\hline A & Mineralizing agent & $\mathrm{NaOH}$ & $\mathrm{KOH}$ & $\mathrm{LiOH}$ \\
\hline B & $\begin{array}{l}\text { Amount of mineralizing } \\
\text { agent (eq. wt) }\end{array}$ & 0.095 & 0.119 & 0.143 \\
\hline $\mathrm{C}$ & Crystallizing time (h) & 8 & 16 & 24 \\
\hline $\mathrm{D}$ & $\begin{array}{l}\text { Crystallizing temperature } \\
\qquad\left({ }^{\circ} \mathrm{C}\right)\end{array}$ & 120 & 150 & 175 \\
\hline $\mathrm{E}$ & Stirring speed (rpm) & 100 & 350 & 600 \\
\hline
\end{tabular}

\section{Fusion method}

In this two-stage method, in addition to the factors evaluated for the direct method, two more factors were added: fusion treatment temperature and time. Furthermore, lower crystallizing temperatures were studied $\left(90-150^{\circ} \mathrm{C}\right)$ and the quantity of mineralizing agent was increased (0.1193-0.1990 eq. wt.) in comparison with the ranges studied in the direct method. In this fusion method the quantity of fly ash and the $\mathrm{H}_{2} \mathrm{O} / \mathrm{SiO}_{2}$ ratio were also kept constants. Table 3 shows the evaluated factors and their corresponding levels.

The methodology was as follows: fly ash and mineralizing agent were homogenized in a porcelain mortar. The mixture was placed in a nickel crucible and heat treated at the selected temperature $\left(200,400\right.$ or $\left.600^{\circ} \mathrm{C}\right)$ for different periods of time $(0.5,1$ and $2 \mathrm{~h})$. The fusion product was recollected, homogenized and transferred into a flask. Then, deionized water was added and the mixture was stirred for $17 \mathrm{~h}$ at room temperature. Once the ageing stage was finished, the mixture was poured into the Parr ${ }^{\circledR}$ reactor where crystallization took place at temperatures of 90,120 or $150^{\circ} \mathrm{C}$ for 8,16 or $24 \mathrm{~h}$. The crystallizing product was washed with deionized water and dried at $100^{\circ} \mathrm{C}$ overnight.

Table 3. Factors and levels evaluated in the fusion method.

\begin{tabular}{|c|c|c|c|c|}
\hline & FACTOR & Level 1 & Level 2 & Level 3 \\
\hline A & Mineralizing agent & $\mathrm{NaOH}$ & $\mathrm{KOH}$ & $\mathrm{LiOH}$ \\
\hline $\mathrm{B}$ & $\begin{array}{c}\text { Amount of mineralizing } \\
\text { agent (eq. wt) }\end{array}$ & 0.1193 & 0.1590 & 0.1990 \\
\hline $\mathrm{C}$ & Fusion temperature $\left({ }^{\circ} \mathrm{C}\right)$ & 200 & 400 & 600 \\
\hline $\mathrm{D}$ & Fusion time (h) & 0.5 & 1 & 2 \\
\hline E & $\begin{array}{c}\text { Crystallizing temperature } \\
\left({ }^{\circ} \mathrm{C}\right)\end{array}$ & 90 & 120 & 150 \\
\hline F & Crystallizing time (h) & 8 & 16 & 24 \\
\hline G & Stirring speed (rpm) & 100 & 350 & 600 \\
\hline
\end{tabular}

Synthesis of faujasite and analcime zeolites from pure materials

In order to compare the zeolitic materials obtained from fly ash, two zeolites: analcime and faujasite were prepared using reactive grade materials as a source of alumina and silica. Faujasite was obtained according to method reported by Lechert et al ${ }^{17}$. Two solutions of sodium aluminate, $1.24 \mathrm{Na}_{2} \mathrm{O}: 0.125 \mathrm{Al}_{2} \mathrm{O}_{3}: 37.74: \mathrm{H}_{2} \mathrm{O}$ and $1.316 \mathrm{Na}_{2} \mathrm{O}: 1.09 \mathrm{SiO}_{2}: 41.32 \mathrm{H}_{2} \mathrm{O}$ were prepared. Both solutions were mixed and homogenized during $30 \mathrm{~min}$. Cristallization was carried out at $90^{\circ} \mathrm{C}$ during $8 \mathrm{~h}$. Product was recovered, washed and dried at $100^{\circ} \mathrm{C}$.

On the other hand, analcime was synthesized as follows; a solution of molar composition $0.03 \mathrm{Al}_{2} \mathrm{O}_{3}: 0.93 \mathrm{SiO}_{2}: 0.48 \mathrm{NaO}: 19.2 \mathrm{H}_{2} \mathrm{O}$ was prepared, crystallization was performed in a reactor Parr of $1 \mathrm{~L}$, at $175^{\circ} \mathrm{C}$; during $8 \mathrm{~h}$. Final product was recovered, washed and dried at $100^{\circ} \mathrm{C}$.

\section{Characterization method}

The crystallization products were characterized by $\mathrm{X}$ ray Diffraction (XRD, Xpert Philips PW3040). The reflection angle (20) was within the range of 10 to $60^{\circ}$. The crystalline phases were identified by means of the JCPDSInternational Centre for Diffraction Data.

To quantify the zeolitic phase obtained a Sietronics Traces 3.0 software was used.
This software is based on the determination of the area under the curve of a XRD pattern, and then the relative intensity in JCPDS cards is used to calculate the relative amount of each crystalline phase. Several investigations have reported the application of this method with good results. Iqbal and Lee ${ }^{18}$ studied the microstructure of aluminous porcelain, to calculate the amount of mullite, quartz and corundum present in the porcelain by comparing the area under the XRD peaks of these phases using Sietronics Traces Processing Software version 2.0. JCPDS cards for quartz, mullite and corundum were used to identify crystal phases. The amount of glass present was estimated by subtracting the sum of the percents of crystalline phases from 100.

Zheng et al ${ }^{19}$, examined the effect of sintering temperature on perovskite phase stability at the surface of $\mathrm{a} \mathrm{Pb}_{0.88} \mathrm{Sr}_{0.12}-\mathrm{Zr}_{0.54} \mathrm{Ti}_{0.44} \mathrm{Sb}_{0.02} \mathrm{O}_{3}$ (PSZT) soft piezoelectric ceramics. X-ray diffraction and scanning (SEM) and transmission (TEM) electron microscopy were used to study the phase assemblage and microstructure. In order to quantify perovskite and second phases, a Sietronics v 2.0 software was used. The JCPDS cards for tetragonal $\mathrm{PbZr}_{0.52} \mathrm{Ti}_{0.48} \mathrm{O}_{3}$ 0784) and monoclinic $\mathrm{ZrO}_{2}$ (37-1484) were used to identify and quantify phases.

Both versions of Sietronics Traces software (2.0 and 3.0) perform quantitative phases analysis from X-ray powder diffraction patterns. The difference between version 3.0 Sietronics Traces and previous version (2.0) lies in format files are supported. Sietronics version 3.0 software can use noninteger values for the readings and this may make some files invalid with earlier versions.

\section{Quantification of the zeolitic phase}

Quantification of the zeolitic phase obtained was performed using Sietronics Traces 3.0 software. The following JCPDS cards were used to identified the crystalline phases obtained; 76-0901 (analcime), 71-0962 (P1 zeolite), 39-0218 (faujasite), 86-1110 (W zeolite), 80-0463 (ABW zeolite), 85-0798 (quartz) and 79-1457 (mullite).

The area under each XRD peak was measured. The sum of the areas under the diffraction peaks corresponding to each of the phases was calculated. The total area was assumed to be $100 \%$. Thus, the percentage of each phase detected was calculated according to the following the equation 1 :

Percentage of crystalline phase $(A)=\frac{\text { sum of the area under peaks of phase }(A)}{\text { Total area }}$

In the cases in which two or more phases were overlapped in one XRD peak, the percentage corresponding to each phase was calculated using the reported intensity (I) in the crystallographic cards (Eq. 2).

$$
\text { Area of phase }(A)=\frac{(\text { Area of peak })\left(I_{A}\right)}{\left(I_{A}+\mathrm{I}_{\mathrm{B}}+\mathrm{I}_{\mathrm{C}}\right)}
$$

\section{RESULTS AND DISCUSSION}

\section{Direct method}

\section{Statistical Analysis}

The zeolitic phases obtained by using the direct method were analcime and zeolites $\mathrm{W}, \mathrm{P}$ and $\mathrm{ABW}$. The percentage of the majoritary zeolitic phase in each treatment was statistically analyzed (variance analysis and calculation of the optimal experimental condition). The nomenclature used in the statistical analysis is as follows:

$\begin{array}{llll}\text { ANOVA } & \text { Variance analysis } & \boldsymbol{F} & \text { Variance ratio } \\ \boldsymbol{d} \boldsymbol{F} & \text { Degrees of freedom } & \boldsymbol{P} & \text { Percent of contribution } \\ \boldsymbol{V} & \text { Mean squares } & \text { Error } & \text { Error (experimental) } \\ \boldsymbol{S} & \text { Sum of squares } & & \\ \boldsymbol{F}_{(\alpha, f 1, f 2)} & \text { F tables, } \alpha \text { confidence, } & \text { fl degrees of freedom of numerator, f2 } \\ \text { degrees of freedom of denominator. This value was taken from Roy Ranjit }{ }^{15}\end{array}$

Variance analysis

Table 4 shows the ANOVA corresponding to the direct method. The statistically significant factors are the mineralizing agent, the crystallizing time and temperature and the quantity of mineralizing agent. The most important factor is the mineralizing agent, which contributes with the $73 \%$ to the response variable. This may be explained taking into account the activation degree of the mineralizing agent on the fly ash, since this favors the de-polimerization/ polymerization reactions that lead to the nucleation and growth of the zeolitic material. 
Table 4. Variance analysis of the direct method.

\begin{tabular}{|l|c|c|c|c|c|r|}
\hline Factor & Df & S & V & F & F $_{(0.05,2,16)}$ & \multicolumn{1}{|c|}{ P } \\
\hline A & 2 & 5335.267 & 2667.633 & $306.957^{*}$ & 3.634 & 73.202 \\
\hline B & 2 & 149.867 & 74.933 & $8.622^{*}$ & 3.634 & 2.056 \\
\hline C & 2 & 1320.907 & 660.454 & $75.997^{*}$ & 3.634 & 18.123 \\
\hline D & 2 & 341.264 & 170.632 & $19.634^{*}$ & 3.634 & 4.682 \\
\hline E & 2 & 2.013 & 1.007 & 0.116 & 3.634 & 0.028 \\
\hline Error & 16 & 139.049 & 8.691 & & & 1.908 \\
\hline Total & 26 & 7288.368 & & & & \\
\hline
\end{tabular}

* Factor statistically significant at 5\%

Calculation of the optimal conditions

The optimal performance $\left(\mathrm{Y}_{\mathrm{on}}\right)$ was calculated from the average value of the treatments plus the sum of the contributions of this factor above the optimal performance ${ }^{15}$ :

$Y_{\text {opt }}=\frac{T}{N}+\left(\bar{A}_{i}-T / N\right)+\left(\bar{B}_{j}-T / N\right)+\left(\bar{C}_{k}-T / N\right)+\ldots\left(\bar{M}_{n}-T / N\right)$

Where $Y_{\text {opt }}$ is the performance at optimum condition, $T$ is the sum of all the results, $N$ is the total number of results, $A, B, C \ldots M$ is the average value of all the statistically significant factors.

The optimal conditions for obtaining a majoritary zeolitic material by the direct method are shown in Table 5. The optimal mineralizing agent is $\mathrm{KOH}$. This may be due to the fact that $\mathrm{KOH}$ is a strong base that dissolves, not only the amorphous material present in the fly ash, but also the mullite and quartz phases. The optimal quantity of agent is the maximum quantity tested. This is due to higher alkalinity reached, since the release of soluble species that lead to the zeolite nucleation and growth is favored at higher $\mathrm{pH}$ and temperature $\left(175^{\circ} \mathrm{C}\right)$ for long periods of time $(16 \mathrm{~h})$. The value of $\mathrm{Y}$ is slightly higher than that reported by Querol et al ${ }^{12}$, who also reported that the zeolitic phase content was within the range of $40-75 \%$ by treating different fly ashes at different experimental conditions.

Table 5. Optimum conditions of zeolitization by the direct method.

\begin{tabular}{|l|l|l|}
\hline & \multicolumn{2}{|c|}{ Optimum conditions } \\
\hline & Mineralizing agent & KOH \\
\hline & Quantity of mineralizing agent & 0.143 eq. wt \\
\hline $\mathbf{Y}_{\text {opt }}=\mathbf{7 7 . 7 4 \%}$ & Crystallizing temperature & $175^{\circ} \mathrm{C}$ \\
\hline & Crystallizing time & $16 \mathrm{~h}$ \\
\hline & Stirring speed & $600 \mathrm{rpm}$. \\
\hline
\end{tabular}

Zeolitization of fly ash following the synthesis conditions obtained from statistical analysis: direct method

Zeolitization of fly ash by direct method was carried out under conditions obtained from statistical analysis and described in Table 5. It can be observed from figure 1 that zeolitic phase, obtained after hydrothermal treatment with $\mathrm{KOH}$ at $175^{\circ} \mathrm{C}$ during $16 \mathrm{~h}$, was $\mathrm{W}$ zeolite without the presence of quartz and mullite, the percent of $\mathrm{W}$ zeolite was $75 \%$ with the rest corresponding to amorphous phase. Experimental results (XRD pattern) corroborated the statistical results, indicating that potassium hydroxide is the best mineralizing agent, this hydroxide dissolve the amorphous phase as well as crystalline phases present in fly ash.

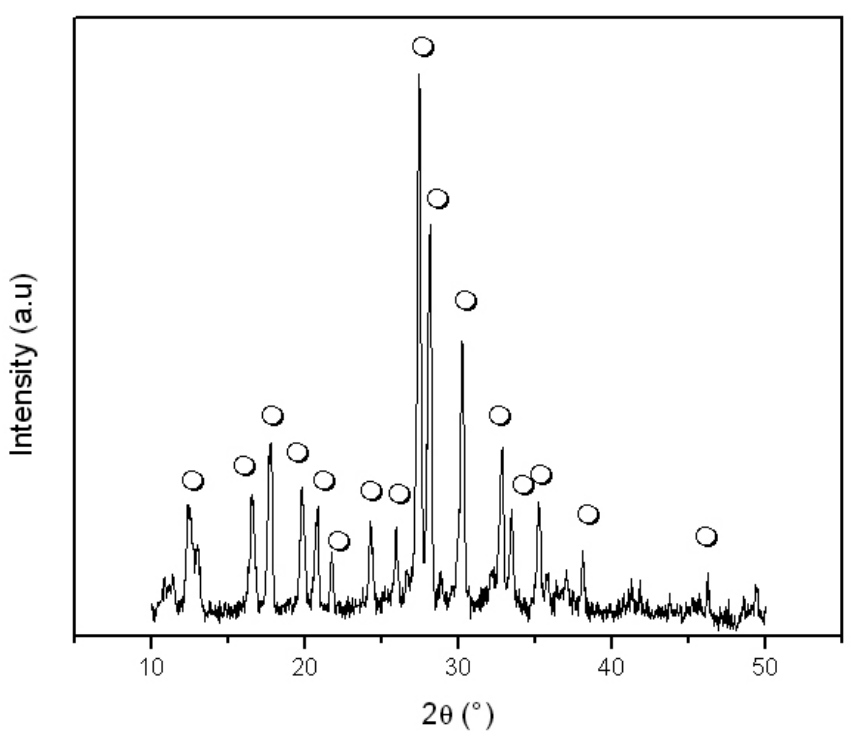

Figure 1: XRD pattern of zeolitic material obtained from fly ash at optimum conditions by direct method. $\left[\mathrm{KOH}, 0.143 \mathrm{eq}, 175^{\circ} \mathrm{C}, 16 \mathrm{~h}, \bigcirc \mathrm{W}\right.$ zeolite, JCPDS Card: 86-1110].

Statistical analysis performed in base of the type of zeolite obtained by the direct method.

In order to evaluate the contribution of each factor on the synthesis of a specific zeolite a statistical analysis was performed. A value of zero was assigned to the response variable of those treatments by which not a specific zeolitic material was obtained. The optimal conditions for obtaining each type of zeolite were also determined.

Variance analysis

Table 6 shows the ANOVA for each type of zeolite. For obtaining zeolites $\mathrm{P}, \mathrm{ABW}$ and analcime all the factors were statistically significant, apart from stirring speed. In the case of W-type zeolite, stirring speed is a significant factor, however its contribution to the response variable is minimal. The nature of the mineralizing agent is the strongest factor on the type of zeolite, thus, this factor requires to be controlled. 
Table 6. Variance analysis of zeolites obtained by the direct method

\begin{tabular}{|c|c|c|c|c|c|c|c|}
\hline Zeolite & Factor & dF & $\mathbf{S}$ & $\mathbf{V}$ & $\mathbf{F}$ & $F_{(0.05,2,16)}$ & $\mathbf{P}$ \\
\hline & A & 2 & 1099.20449 & 549.602247 & 3911.97943* & 3.6337 & 24.9856294 \\
\hline & B & 2 & 1099.20449 & 549.602247 & $3911.97943 *$ & 3.6337 & 24.9856294 \\
\hline & $\mathrm{C}$ & 2 & 1099.20449 & 549.602247 & 3911.97943* & 3.6337 & 24.9856294 \\
\hline \multirow[t]{7}{*}{$\mathbf{P}$} & $\mathrm{D}$ & 2 & 1099.20449 & 549.602247 & 3911.97943* & 3.6337 & 24.9856294 \\
\hline & $\mathrm{E}$ & 2 & 0.28098422 & 0.14049211 & 1 & 3.6337 & 0.00638695 \\
\hline & Error & 16 & 2.24787377 & 0.14049211 & & & 0.05109563 \\
\hline & Total & 26 & 4399.34683 & & & & \\
\hline & $\mathrm{A}$ & 2 & 8627.43917 & 4313.71959 & $8713.67469^{*}$ & 3.6337 & 55.587641 \\
\hline & B & 2 & 2294.28787 & 1147.14393 & $2317.22041 *$ & 3.6337 & 14.7823761 \\
\hline & $\mathrm{C}$ & 2 & 2294.28787 & 1147.14393 & $2317.22041 *$ & 3.6337 & 14.7823761 \\
\hline \multirow[t]{7}{*}{ Analcime } & $\mathrm{D}$ & 2 & 2294.28787 & 1147.14393 & $2317.22041 *$ & 3.6337 & 14.7823761 \\
\hline & $\mathrm{E}$ & 2 & 2.20327607 & 1.10163803 & 2.2252989 & 3.6337 & 0.01419598 \\
\hline & Error & 16 & 7.92082742 & 0.49505171 & & & 0.05103486 \\
\hline & Total & 26 & 15520.4269 & & & & \\
\hline & A & 2 & 21942.144 & 10971.072 & 15120.434* & 3.6337 & 96.747012 \\
\hline & $\mathrm{B}$ & 2 & 240.18162 & 120.09081 & $165.51028^{*}$ & 3.6337 & 1.0590056 \\
\hline & $\mathrm{C}$ & 2 & 240.18162 & 120.09081 & $165.51028 *$ & 3.6337 & 1.0590056 \\
\hline \multirow[t]{7}{*}{$\mathbf{W}$} & $\mathrm{D}$ & 2 & 240.18162 & 120.09081 & $165.51028^{*}$ & 3.6337 & 1.0590056 \\
\hline & $\mathrm{E}$ & 2 & 5.6208667 & 2.8104333 & $3.8733655^{*}$ & 3.6337 & 0.0247835 \\
\hline & Error & 16 & 11.609267 & 0.7255792 & & & 0.0511874 \\
\hline & Total & 26 & 22679.919 & & & & \\
\hline & $\mathrm{A}$ & 2 & 4434.2903 & 2217.1452 & $349.20017 *$ & 3.6337 & 94.447356 \\
\hline & $\mathrm{B}$ & 2 & 49.838825 & 24.919412 & $3.9248052 *$ & 3.6337 & 1.0615329 \\
\hline & $\mathrm{C}$ & 2 & 49.838825 & 24.919412 & $3.9248052 *$ & 3.6337 & 1.0615329 \\
\hline \multirow[t]{4}{*}{ ABW } & $\mathrm{D}$ & 2 & 49.838825 & 24.919412 & $3.9248052 *$ & 3.6337 & 1.0615329 \\
\hline & $\mathrm{E}$ & 2 & 9.5920423 & 4.7960211 & 0.7553729 & 3.6337 & 0.204304 \\
\hline & Error & 16 & 101.58736 & 6.3492099 & & & 2.1637414 \\
\hline & Total & 26 & 4694.9862 & & & & \\
\hline
\end{tabular}

* Factor statistically significant at $5 \%$

Calculation of the optimal conditions

Table 7 shows the optimal conditions for obtaining each type of zeolite. The calculated $\mathrm{Y}_{\text {opt }}$ value is close to that obtained from the experiments. The optimal mineralizing agents for the synthesis of a specific zeolite are: $\mathrm{NaOH}$ for the P-type zeolite and antalcime, $\mathrm{KOH}$ for the W-type zeolite and LiOH for the ABW-type zeolite.

Table 7. Optimum conditions of synthesis of zeolites by the direct method.

\begin{tabular}{|l|c|c|c|c|c|c|c|}
\hline & \multicolumn{5}{|c|}{ Factors } & $\mathbf{Y}_{\text {opt }}$ & $\mathbf{Y}_{\text {opt }}$ \\
\hline Zeolita & $\mathbf{A}$ & $\mathbf{B}$ & $\mathbf{C}$ & $\mathbf{D}$ & $\mathbf{E}$ & calculated & Experimental \\
\hline$P$ & $\mathrm{NaOH}$ & $0.095 \mathrm{eq}$ & $120^{\circ} \mathrm{C}$ & $8 \mathrm{~h}$ & $350 \mathrm{rpm}$ & $40.62 \%$ & $41.40 \%$ \\
\hline Analcime & $\mathrm{NaOH}$ & $0.143 \mathrm{eq}$ & $175^{\circ} \mathrm{C}$ & $24 \mathrm{~h}$ & $350 \mathrm{rpm}$ & $65.16 \%$ & $66.45 \%$ \\
\hline$W$ & $\mathrm{KOH}$ & $0.095 \mathrm{eq}$ & $175^{\circ} \mathrm{C}$ & $16 \mathrm{~h}$ & $350 \mathrm{rpm}$ & $73.12 \%$ & $74.57 \%$ \\
\hline$A B W$ & $\mathrm{LiOH}$ & $0.119 \mathrm{eq}$ & $175^{\circ} \mathrm{C}$ & $8 \mathrm{~h}$ & $100 \mathrm{rpm}$ & $30.49 \%$ & $33.86 \%$ \\
\hline
\end{tabular}

\section{Synthesis of analcime, $P, W$ and $A B W$ zeolites from fly ash using conditions determined by statistical analysis}

Zeolites analcime, P, W and ABW were synthesized from fly ash by the direct method using the conditions described in Table 7. Figure 2 shows the XRD patterns of analcime obtained from fly ash (Fig, 2a) and analcime synthesized from pure silica and alumina sources (Fig. 2b). It was not detected the presence of mullite and quartz. Both XRD patterns show the same reflections and this suggests that fly ash is a suitable material to synthesize analcime. 


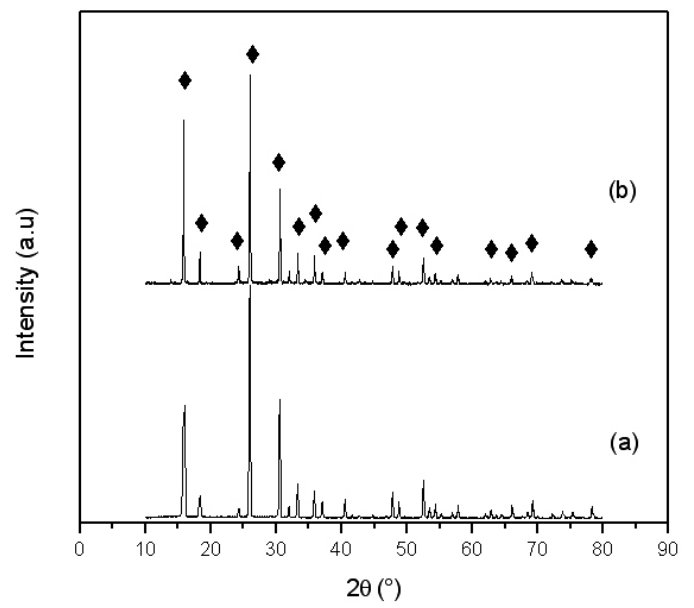

Figure 2: XRD patterns of analcime zeolite synthesized by the direct method from a) fly ash and b) reactive grade materials [ analcime zeolite, JCPDS Card: 76-0901].

Zeolites $\mathrm{P}, \mathrm{W}$ and $\mathrm{ABW}$ were obtained using $\mathrm{NaOH}, \mathrm{KOH}$ and $\mathrm{LiOH}$ as mineralizing agent, respectively. The synthesis conditions used to obtain these zeolitic phases correspond to the conditions reported in Table 7. Figure 3 shows the XRD patterns of these zeolites. X ray patterns for zeolite P (Fig. 3a) and zeolite ABW (Fig.3c) were detected the presence of quartz and mullite, while W zeolite (Fig. 3b) was obtained as unique phase. This is in agreement to the results of statistical analysis which showed that $\mathrm{KOH}$ was the main factor for crystallization of zeolites by direct method. ABW zeolite was synthesized using $\mathrm{LiOH}$, which is a slower mineralizing agent of fly ash compared to $\mathrm{KOH}$ and $\mathrm{NaOH}$, which could explain the presence of peaks of mullite and quartz.

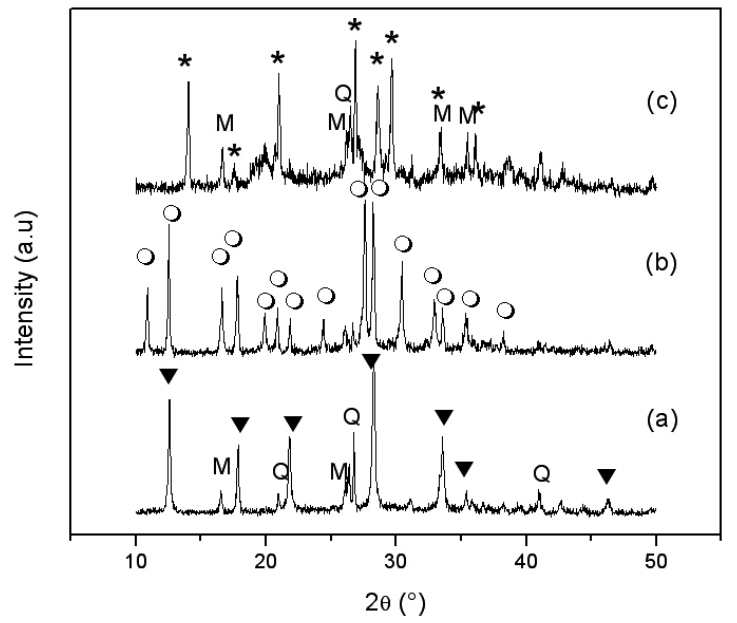

Figure 3: XRD patterns of zeolites synthesized from fly ash by direct method under optimal conditions a) P zeolite, b) W zeolite and c) ABW zeolite. [ $\boldsymbol{\nabla}=\mathrm{P}, \bigcirc=\mathrm{W}, *=\mathrm{ABW}]$. JCPDS Cards: 71-0962 (P zeolite), 86-1110 (W zeolite) and 80-0463 (ABW zeolite)].

\section{Fusion method}

The zeolitization of fly ash using the fusion method lead to 5 different types of zeolites: P, analcime, faujasite, $\mathrm{W}$ and $\mathrm{ABW}$. The statistical analysis performed was similar to that of the direct method.

\section{Statistical analysis \\ Variance analysis}

According to the ANOVA results (Table 8) the statistically significant factors for obtaining a majoritary zeolitic phase by using the fusion method are: crystallizing temperature, type of mineralizing agent, stirring speed and fusion temperature, being the first two above mentioned (E and $\mathrm{A}$ ) the most important factors and need to be controlled during the process. The total contribution of these two factors to the response variable is about $50 \%$.
Table 8. Variance analysis of the fusion method.

\begin{tabular}{|l|c|c|c|c|c|c|}
\hline Factor & $\mathbf{d F}$ & $\mathbf{S}$ & $\mathbf{V}$ & $\mathbf{F}$ & $\begin{array}{c}\mathbf{F}_{(\mathbf{0 . 0 5},} \\
\text { 2,12) }\end{array}$ & $\mathbf{P}$ \\
\hline A & 2 & 5105.0918 & 2552.5459 & $11.778319^{*}$ & 3.8853 & 22.821679 \\
\hline B & 2 & 659.70232 & 329.85116 & 1.5220459 & 3.8853 & 2.9491173 \\
\hline C & 2 & 2427.2769 & 1213.6384 & $5.6001424 *$ & 3.8853 & 10.85084 \\
\hline D & 2 & 201.46899 & 100.73449 & 0.4648234 & 3.8853 & 0.9006421 \\
\hline E & 2 & 5969.3968 & 2984.6984 & $13.772418 *$ & 3.8853 & 26.685447 \\
\hline F & 2 & 1521.6212 & 760.8106 & 3.5106401 & 3.8853 & 6.8022186 \\
\hline G & 2 & 3884.3384 & 1942.1692 & $8.9618322 *$ & 3.8853 & 17.364452 \\
\hline Error & 12 & 2600.5877 & 216.71564 & & & 11.625604 \\
\hline Total & 26 & 22369.484 & & & & 100 \\
\hline
\end{tabular}

* Factor statistically significant at 5\%

Calculation of the optimal conditions

The optimal conditions for the zeolitization of fly ash by the fusion method are shown in Table 9. The optimal mineralizing agent is $\mathrm{NaOH}$, which favors the dissolution of the crystalline phases of fly ash during fusion at high temperature $\left(600^{\circ} \mathrm{C}\right)$ for periods of $2 \mathrm{~h}$. In order to obtain $91 \%$ of zeolitic phase during crystallizing at $150{ }^{\circ} \mathrm{C}$, short times are required $(8 \mathrm{~h})$.

Table 9. Optimum conditions of zeolitization by the fusion method.

\begin{tabular}{|l|l|l|}
\hline & \multicolumn{2}{|c|}{ Optimum conditions } \\
\hline & Mineralizing agent & $\mathrm{NaOH}$ \\
\hline & Quantity of mineralizing agent & 0.1193 eq. wt \\
\hline \multirow{3}{*}{$\mathbf{Y}_{\text {opt }}=\mathbf{9 1 . 0 5 \%} \%$} & Fusion temperature & $600^{\circ} \mathrm{C}$ \\
& Fusion time & $2 \mathrm{~h}$ \\
& Crystallizing temperature & $150^{\circ} \mathrm{C}$ \\
\hline & Crystallizing time & $8 \mathrm{~h}$ \\
\hline & Stirring speed & $350 \mathrm{rpm}$. \\
\hline
\end{tabular}

Zeolitization of fly ash following the synthesis conditions obtained from statistical analysis

Zeolitization of fly ash by fusion method was performed using the conditions obtained from statistical analysis and described in Table 9. Figure 4 shows XRD patterns of zeolite obtained from fly ash by fusion method, submitted to alkali treatment with $\mathrm{NaOH}$ at $600^{\circ} \mathrm{C}$, for $2 \mathrm{~h}$ and subsequently hydrothermal treatment at $150^{\circ} \mathrm{C}$, during $8 \mathrm{~h}$. Zeolitic phase obtained was analcime, mullite and quartz were not detected. The percent of analcime was $92 \%$ with the rest corresponding to amorphous phase. These results confirmed the statistical analysis that indicated that $\mathrm{NaOH}$ is the best mineralizing agent for zeolitization of fly ash by fusion method.

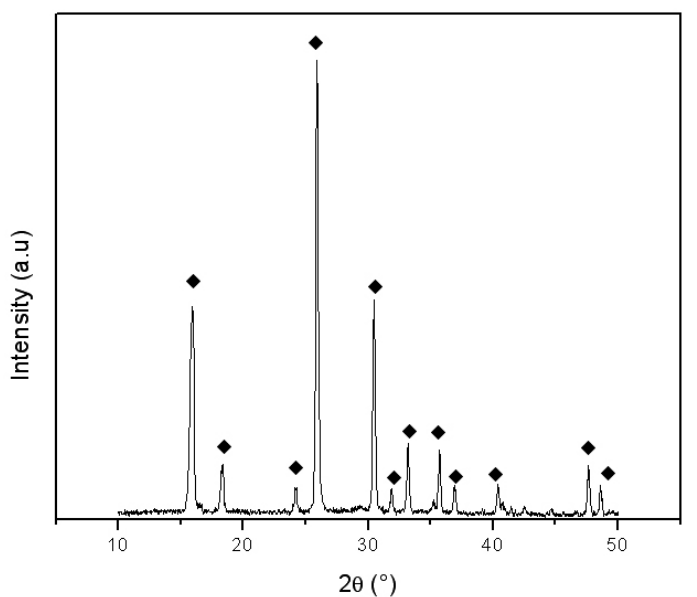

Figure 4: XRD pattern of zeolitic material obtained from fly ash at optimum conditions by the fusion method. $\left[\mathrm{NaOH}, 0.1193 \mathrm{eq}, 600^{\circ} \mathrm{C}, 2 \mathrm{~h}\right.$ and crystallization at $150^{\circ} \mathrm{C}, 8 \mathrm{~h}$, anacilme zeolite, JCPDS card: 76-0901]. 
Statistical analysis performed in base of the type of zeolite obtained by the fusion method.

Variance analysis

Table 10 shows the ANOVA of the different zeolites obtained by the fusion method. The type of mineralizing agent, the crystallizing temperature and time, and stirring speed are the statistically significant factors for obtaining faujasite, analcime, P-type and W-type zeolites. In the case of the ABW-type zeolite, the significant factors are: the mineralizing agent, fusion temperature and time, and stirring speed.

Each of the zeolitic phases obtained by using this method was the only zeolite present and no other crystalline phases, such as mullite and quartz, were obtained, with the exception of the synthesis of the ABW-type, where quartz and mullite are also present. This may be due to the slow dissolution of these phases by using $\mathrm{LiOH}$ as activating agent of fly ash.

Table 10. Variance analysis of zeolites obtained by the fusion method.

\begin{tabular}{|c|c|c|c|c|c|c|c|}
\hline Zeolite & Factor & dF & $\mathbf{S}$ & V & $\mathbf{F}$ & Ftab & $\mathbf{P}$ \\
\hline & A & 2 & 928.5216 & 464.2608 & $6.7971 *$ & 3.8853 & 18.782588 \\
\hline & B & 2 & 136.60409 & 68.302044 & 1 & 3.8853 & 2.7632942 \\
\hline & $\mathrm{C}$ & 2 & 136.60409 & 68.302044 & 1 & 3.8853 & 2.7632942 \\
\hline \multirow[t]{9}{*}{ Faujasite } & $\mathrm{D}$ & 2 & 136.60409 & 68.302044 & 1 & 3.8853 & 2.7632942 \\
\hline & $\mathrm{E}$ & 2 & 928.5216 & 464.2608 & $6.7971 *$ & 3.8853 & 18.782588 \\
\hline & $\mathrm{F}$ & 2 & 928.5216 & 464.2608 & $6.7971 *$ & 3.8853 & 18.782588 \\
\hline & G & 2 & 928.5216 & 464.2608 & $6.7971 *$ & 3.8853 & 18.782588 \\
\hline & Error & 16 & 819.62453 & 68.302044 & & 3.8853 & 16.579765 \\
\hline & Total & 26 & 4943.5232 & & & & 100 \\
\hline & $\mathrm{A}$ & 2 & 1945.2002 & 972.6001 & $191.5869 *$ & 3.8853 & 24.7098 \\
\hline & $\mathrm{B}$ & 2 & 10.153096 & 5.076548 & 1 & 3.8853 & 0.12897 \\
\hline & $\mathrm{C}$ & 2 & 10.153096 & 5.076548 & 1 & 3.8853 & 0.12897 \\
\hline \multirow[t]{9}{*}{$\mathbf{P}$} & $\mathrm{D}$ & 2 & 10.153096 & 5.076548 & 1 & 3.8853 & 0.12897 \\
\hline & $E$ & 2 & 1945.2002 & 972.6001 & 191.5869* & 3.8853 & 24.7098 \\
\hline & $\mathrm{F}$ & 2 & 1945.2002 & 972.6001 & $191.5869^{*}$ & 3.8853 & 24.7098 \\
\hline & $\mathrm{G}$ & 2 & 1945.2002 & 972.6001 & $191.5869^{*}$ & 3.8853 & 24.7098 \\
\hline & Error & 16 & 60.918577 & 5.076548 & & & 0.77384 \\
\hline & Total & 26 & 7872.1786 & & & & 100 \\
\hline & $\mathrm{A}$ & 2 & 669.3632 & 334.6816 & $3.9996 *$ & 3.8853 & 15.99944 \\
\hline & $\mathrm{B}$ & 2 & 167.3570 & 83.6785 & 1 & 3.8853 & 4.000247 \\
\hline & $\mathrm{C}$ & 2 & 167.3570 & 83.6785 & 1 & 3.8853 & 4.000247 \\
\hline \multirow[t]{9}{*}{ Analcime } & $\mathrm{D}$ & 2 & 167.3570 & 83.6785 & 1 & 3.8853 & 4.000247 \\
\hline & $\mathrm{E}$ & 2 & 669.3632 & 334.6816 & $3.9996 *$ & 3.8853 & 15.99944 \\
\hline & $\mathrm{F}$ & 2 & 669.3632 & 334.6816 & $3.9996 *$ & 3.8853 & 15.99944 \\
\hline & $\mathrm{G}$ & 2 & 669.3632 & 334.6816 & 3.9996* & 3.8853 & 15.99944 \\
\hline & Error & 16 & 1004.1420 & 83.6785 & & & 24.00149 \\
\hline & Total & 26 & 4183.6660 & & & & 100 \\
\hline & $\mathrm{A}$ & 2 & 7442.6904 & 3721.3452 & $25.1122 *$ & 3.8853 & 34.187274 \\
\hline & $\mathrm{B}$ & 2 & 380.15469 & 190.07734 & 1.28267 & 3.8853 & 1.7462035 \\
\hline & $\mathrm{C}$ & 2 & 380.15469 & 190.07734 & 1.28267 & 3.8853 & 1.7462035 \\
\hline \multirow[t]{9}{*}{$\mathbf{W}$} & $\mathrm{D}$ & 2 & 380.15469 & 190.07734 & 1.28267 & 3.8853 & 1.7462035 \\
\hline & $\mathrm{E}$ & 2 & 3802.9793 & 1901.4896 & $12.8315^{*}$ & 3.8853 & 17.468615 \\
\hline & $\mathrm{F}$ & 2 & 3802.9793 & 1901.4896 & $12.8315^{*}$ & 3.8853 & 17.468615 \\
\hline & $\mathrm{G}$ & 2 & 3802.9793 & 1901.4896 & $12.8315^{*}$ & 3.8853 & 17.468615 \\
\hline & Error & 16 & 1778.2615 & 148.18846 & & & 8.1682709 \\
\hline & Total & 26 & 21770.354 & & & & 100 \\
\hline & $\mathrm{A}$ & 2 & 1417.6263 & 708.81317 & $18.713393 *$ & 3.8853 & 40.036387 \\
\hline & $\mathrm{B}$ & 2 & 435.14059 & 217.57029 & $5.7440783 *$ & 3.8853 & 12.289174 \\
\hline & $\mathrm{C}$ & 2 & 435.14059 & 217.57029 & $5.7440783 *$ & 3.8853 & 12.289174 \\
\hline \multirow[t]{6}{*}{ ABW } & $\mathrm{D}$ & 2 & 435.14059 & 217.57029 & $5.7440783^{*}$ & 3.8853 & 12.289174 \\
\hline & $E$ & 2 & 121.08963 & 60.544815 & 1.598445 & 3.8853 & 3.4197949 \\
\hline & $\mathrm{F}$ & 2 & 121.08963 & 60.544815 & 1.598445 & 3.8853 & 3.4197949 \\
\hline & G & 2 & 121.08963 & 60.544815 & 1.598445 & 3.8853 & 3.4197949 \\
\hline & Error & 16 & 454.52784 & 37.87732 & & & 12.836706 \\
\hline & Total & 26 & 3540.8448 & & & & 100 \\
\hline
\end{tabular}

* Factor statistically significant at $5 \%$ 
Calculation of the optimal conditions

Table 11 shows the optimal conditions for obtaining every type of zeolite. In all the cases the values of calculated $Y_{\text {opt }}$ were lower than those obtained from the experiments. This may be attributed to a strong interaction between factors, which was not considered in this experimental array ${ }^{20}$. The percentages of zeolitic phase for the P, W and ABW types are higher than those obtained by the direct method. This indicates that the zeolitization of fly ash is favored with this two-stage method. The fly ash-mineralizing agent mixture submitted to fusion treatment facilitates the formation of highly active aluminates and silicates, which are easily water-soluble and promote the formation of zeolite.

The differences between the calculated and experimental values of $Y_{\text {opt }}$ indicate the necessity of using a new experimental design that allows the determination of the interaction among factors, this in the aim of optimizing the synthesis of the zeolitic phase.

Table 11. Optimum conditions of synthesis of zeolites by the fusion method.

\begin{tabular}{|c|c|c|c|c|c|c|c|c|c|}
\hline & \multicolumn{7}{|c|}{ Factors } & \multirow{2}{*}{$\begin{array}{c}Y_{\text {opt }} \\
\text { calculated }\end{array}$} & \multirow{2}{*}{$\begin{array}{c}\mathbf{Y}_{\text {opt }} \\
\text { experimental }\end{array}$} \\
\hline Zeolite & A & B & $\mathrm{C}$ & D & $\mathbf{E}$ & $\mathbf{F}$ & G & & \\
\hline Faujasite & $\mathrm{NaOH}$ & $0.199 \mathrm{eq}$ & $600^{\circ} \mathrm{C}$ & $2 \mathrm{~h}$ & $90^{\circ} \mathrm{C}$ & $8 \mathrm{~h}$ & 100rpm & $37.32 \%$ & $65.60 \%$ \\
\hline$P$ & $\mathrm{NaOH}$ & $0.199 \mathrm{eq}$ & $600^{\circ} \mathrm{C}$ & $2 \mathrm{~h}$ & $120^{\circ} \mathrm{C}$ & $16 \mathrm{~h}$ & $350 \mathrm{rpm}$ & $54.01 \%$ & $61.81 \%$ \\
\hline Analcime & $\mathrm{NaOH}$ & $0.159 \mathrm{eq}$ & $400^{\circ} \mathrm{C}$ & $1 \mathrm{~h}$ & $150^{\circ} \mathrm{C}$ & $24 \mathrm{~h}$ & 600rpm & $31.68 \%$ & $47.80 \%$ \\
\hline$W$ & $\mathrm{KOH}$ & $0.119 \mathrm{eq}$ & $400^{\circ} \mathrm{C}$ & $2 \mathrm{~h}$ & $150^{\circ} \mathrm{C}$ & $8 \mathrm{~h}$ & $350 \mathrm{rpm}$ & $83.99 \%$ & $87.86 \%$ \\
\hline$A B W$ & $\mathrm{LiOH}$ & $0.199 \mathrm{eq}$ & $600^{\circ} \mathrm{C}$ & $1 \mathrm{~h}$ & $150^{\circ} \mathrm{C}$ & $16 \mathrm{~h}$ & 100rpm & $32.34 \%$ & $54.69 \%$ \\
\hline
\end{tabular}

Synthesis of analcime, faujasite, $P, W$ and $A B W$ zeolites from fly ash using conditions determined by statistical analysis: fusion method

Zeolites analcime, faujasite, $\mathrm{P}, \mathrm{W}$ and $\mathrm{ABW}$ were obtained from fly ash by the fusion method, using the synthesis conditions determined by statistical analysis (Table 11). Figure 5 shows XRD patterns of faujasite and analcime synthesized from fly ash and from pure raw materials. Comparing the XRD patterns for each zeolite synthesized from two different sources of silica and alumina, it can be observed that there are present the same reflections for each one. It was no detected the presence quartz and mullite.

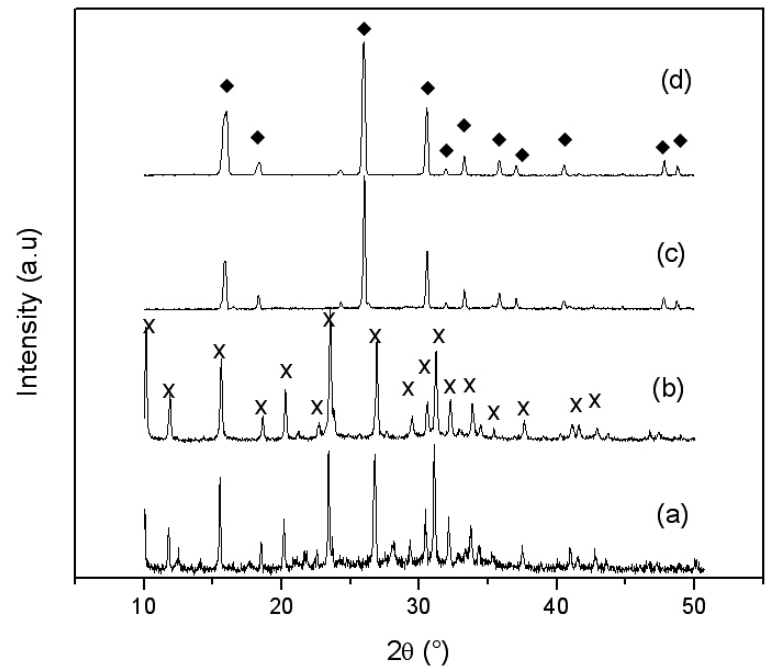

Figure 5: XRD patterns of zeolites synthesized from fly ash by fusion method a) faujasite and c) analcime, and from pure materials b) faujasite and d) analcime. [x, faujasite, analcime. JCPDS cards: 39-0218 (faujasite) and 76-0901 (analcime)]

On the other hand, XRD patterns corresponding to P (Fig. 6a) and ABW (Fig. 6c) zeolites obtained by fusion method showed peaks of mullite and quartz in intensities lower than those detected using the direct method. This can be due to the dissolution of mullite and quartz during alkali heat treatment, favoring the formation of zeolite crystals during hydrothermal treatment. This can be observed in the percentages of these zeolitic phases obtained for each zeolitization method (see Tables 7 and 11).

In case of $\mathrm{W}$ zeolite, it was obtained as unique phase without presence of quartz and mullite (Fig 6b), confirming that potassium hydroxide dissolves these crystalline phases.

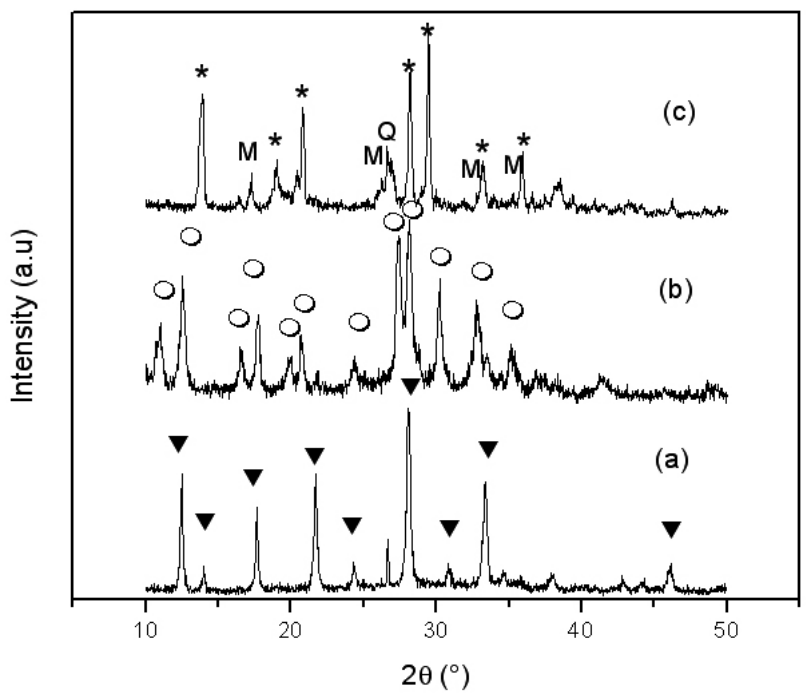

Figure 6: XRD patterns of zeolites synthesized from fly ash by direct method under optimal conditions a) $\mathrm{P}, \mathrm{b}$ ) $\mathrm{W}$ and c) $\mathrm{ABW}$ zeolites. $[\boldsymbol{\nabla}=\mathrm{P}, \mathrm{O}=$ $\mathrm{W}, *=$ ABW, JCPDS cards: 71-0962 (P zeolite), 86-1110 (W zeolite) and 800463 (ABW zeolite)].

According to the results obtained from the statistical analyses and experimental results, the factors that require a strict control during the zeolitization process of fly ash are the type of mineralizing agent and the crystallizing temperature. This is in agreement with that reported in the literature ${ }^{21}$. During the synthesis the mineralizing agent has three main functions: (a) transforms fly ash into mobile species, (b) promotes the chemical reactivity of the mobile species in such a way that they are able to react forming a new chemical bond, such as silicate ions and generates the zeolitic structure and (c) arrays the mobile species in such a way that the new structure is able to exist as a stable solid phase.

The application of an experimental design, as well as the statistical management of data allowed the determination of the factors that need to be considered and controlled during the zeolitization process of fly ash. Although by the obtained information was possible to define the determinant factors on the zeolitization of fly ash, a further research needs to be performed in order to evaluate the effect of the interactions among factors in the aim of optimizing the process. With the optimal conditions obtained so far and with the application of a new experimental array, it would be possible to improve the synthesis of specific zeolites. Once improved the process, a standardized synthesis method can be developed, which may be independent of the composition of the raw 
material requiring only an adjustment of the initial composition of the mixture by adding an external source of $\mathrm{Si}$ or $\mathrm{Al}$ according to it is the case.

\section{CONCLUSIONS}

Two different methods were used for zeolitization of fly ash: a conventional hydrothermal method and a fusion method followed by hydrothermal treatment. Activation of fly ash depended on the nature of the alkali agent and the processing conditions. $\mathrm{KOH}$ promoted formation of zeolite $\mathrm{W}$, by both of the methods studied. However, the fusion treatment allowed the decrease of the crystallizing temperature from 175 to $150^{\circ} \mathrm{C}$ obtaining a higher content of zeolitic phase (90\%) than by the direct method $(75 \%)$. On the other hand, when $\mathrm{NaOH}$ was used, three different zeolites were obtained: $\mathrm{P}$, faujasite and analcime, their crystallinity was improved when the quantity of $\mathrm{NaOH}$ was increased.

The optimal conditions for the zeolitization of fly ash by the direct method were $\mathrm{KOH}$ as alkaline agent, a $\mathrm{KOH} /$ fly ash ratio of 0.5 , and hydrothermal conditions of $175^{\circ} \mathrm{C}$ for $16 \mathrm{~h}$. By the fusion treatment, the optimal conditions were: a NaOH/fly ash ratio of 0.62 , fusion temperature of $600^{\circ} \mathrm{C}$ for $2 \mathrm{~h}$ and hydrothermal conditions of $150^{\circ} \mathrm{C}$ for $8 \mathrm{~h}$.

\section{REFERENCES}

[1] R. Mohapatra and J. R. Rao. J. Chem. Technol. Biotechnol. 76, 9, (2001).

[2] J. Celis, R. Morales, C. Zaror, J. Inzunza, R. Flocchini, O. Carvacho. J. Chil. Chem. Soc. 48, 2, (2003).

[3] Coal Ash: Its Origin, Disposal, Use and potential Health Issues. EPRI, 3412, (1998).

[4] G. Dirk. Waste. Manag. 16 (1-3), 51, (1996).

[5] A. Andres, I. Ortiz, J. R. Viguri., A. Irabien. J. Hazard. Mater. 40, 31, (1995)
[6] S. T. Jarvis, T. G. Brooks. Waste. Manag. 16 (1-3), 135, (1996).

[7] M. Anderson, G. Jackson. Ceram. Trans. J. 82, 2, 34, (1983).

[8] P. Payra and P. K. Dutta. Zeolites: A primer. In Auerbach S. M., Carrado K. A., Dutta P. K. Handbook of zeolites and Technology. CRC Press, 2003; p. 1-19.

[9] A. Singer and V. Berkgaut. Environ. Sci. Technol. 29, 1748, (1995).

[10]J. Scott, D. Guang, K. Naeramitmarnsuk, M. Thabuot and R. Amal. J. Chem. Technol. Biotechnol. 77, 63, (2002).

[11] K. Ojha, C. P. Narayan and S. Amar Nath. Bull. Mater. Sci. 27, 6, 555, (2004).

[12]X. Querol, N. Moreno, J. C.Umaña, F. Plana, A. Alastuey. E. Hernandez, A. López-Soler, F. Plana. International Journal of Coal Geology. 50, 413, (2002).

[13] C. F. Lin, H. C. His. Environ. Sci. Technol. 29, 1109, (1995).

[14]W.H. Shih., H.L. Chang. Mat. Lett. 28, 263, (1996).

[15]R. Ranjit, A primer on the Taguchi Method. Society of Manufacturing Engineers., United States of America, 1990, pp 1-55.

[16] ASTM C618-92A Standard specifications for fly ash and raw or calcinated natural pozzoland for use as mineral admixture in Portland cement concrete. American Society for Testing and Materials, annual book of ASTM Standards, Vol 04.02. Pennsylvania, (1992).

[17]H. Lechert, H. Kacirek. Linde type X in Verified synthesis of zeolitic materials. H.Robson editor, Elsevier Science, Amsterdam, 2001, pp 150151

[18] Y. Iqbal and W. E. Lee. J. Am. Ceram. Soc. 82, 12, 3584, (1999).

[19] H. Zheng, I.M. Reaney, W.L. Lee, N. Jones and H. Thomas. J. Am. Ceram. Soc. 85, 1, 207, (2002).

[20]W. Condra Lloiy. Value-added Management with Design of Experiments. Chapman \& Hall, London 1995, pp 93-138.

[21] S. Cundy Colin, A. Cox Paul. Micropor. Mesopor Mater. 82, 1, (2005). 